\title{
The Influence of Internet and Social Media on Purchasing Decisions in Kuwait
}

\author{
Khalid Abdulkareem Al-Enezi*1, Imad Fakhri Taha Al Shaikhli², \\ Sufyan Salim Mahmood AlDabbagh ${ }^{3}$ \\ ${ }^{1}$ Central Agency for Information Technology-Department of computer science-Kuwait \\ ${ }^{2}$ International Islamic Uuniverisity Malaysia \\ ${ }^{3}$ University of Mosul-Iraq
}

\begin{tabular}{l}
\hline \hline Article Info \\
\hline Article history: \\
Received Nov 17, 2017 \\
Revised Jan 25, 2018 \\
Accepted Feb 19, 2018 \\
\hline
\end{tabular}

Keywords:

Customers

Marketing

Small businesses

Social media

Social Networks

\begin{abstract}
This research aims to measure the role of social networks in influencing purchasing decisions among consumers in Kuwait; the research used the quantitative methods, and analytical the technique to get the results, and the research developed a measure to study the relationship between the variables to the study and selection of a sample of consumers of (100). The results indicated that the social networking variables (exchange of information, evaluation of product) possess influence on purchasing decisions. Furthermore, the results indicate that majority of respondents do their digital scanning more often before intend to go to the store. The unexpected results came from the question "traditional advertising (TV, Newspaper, Magazine, Billboards) are more effective than the social networking; 23\% agreed, 36\% said no, and $41 \%$ said sometimes. In light of these findings, the study made a series of recommendations; the most important are; The executives and sales representatives need to understand the benefits offered by social networks, and understand the advantages and functions and tools of social communication, and knowing how to apply them effectively and efficiently, and then use the appropriate social networking tool.
\end{abstract}

Copyright $@ 2018$ Institute of Advanced Engineering and Science. All rights reserved.

\section{Corresponding Author:}

Khalid Abdulkareem Al-Enezi,

Department of Technolofy and Infrastructure,

Central Agency for Information Technology, Kuwait

Email: alenezi.khaled@yahoo.com

\section{INTRODUCTION}

For a long time, the traditional media such as TV, newspapers, magazines, and Billboards are the focuses of communication that are used to reach out to a large number of audiences, and delivering different messages to them, whether those messages were carrying political, social, or commercial information. The new media is associated with the Internet and social media; World Wide Web can make a person to become a publisher, and send his message to all parts around the world at virtually no cost.

This study seeks to provide characterization of the social networking and their different effects of the exchange of information, product evaluation/ Rating, and consumer support. The most important characteristic of the Internet and social media is that they are providing great freedom space. The Internet and social networks have made great audience to express freely their feelings and opinions, in addition, the wide use of smart phones equipped with digital cameras, and the ability to link to the Internet from anywhere led to raise the ceiling of freedom of expression and access to information, and the ability to connect in an unprecedented way. 


\section{PROBLEM STATMENT}

Social networks have become an influential means of social communication as it allows connection between acquaintances and friends in different society, the social media sites in the unlimited influence and continuing strength, especially for young people, they are the most social media users. Modern societies are extensively use Social Media channels in order to connect people together throughout the world using the Internet. Whether it is media sharing websites blogs, or forums, all are under the category of social networks. Young people can now have interactive discussion, on any subject, political, social, and businesses with almost everybody, permitting them to share their experiences and valuable information. Companies realized that how social media is very effective, powerful and widely used, it represent a large diversity of new opportunities to promote their products, products and services. Key business factors of social media allow consumers to evaluate products, make recommendations to friends and acquaintances share any recent business experience through social media. The research will answer the following questions: Does Social Media affect consumer decision-making. Is there any relationship between use of social media and reaching out to more customers? Is social media advertising become more important than traditional advertisement in TV and press.

\section{IMPORTANCE OF RESEARCH}

The potential influence that social networking is doing is widely noted, and is growing exponentially, as it leads to connect more people to the network. Usually, people tend to talk about things that attract their attention. As the number of people within the network grows, it will attract more people, and thus increasing communication.

Social Networking became Word-of-Mouth; it can cause huge effect on product connection, product awareness, and decision-making. There is a relationship between integration of social media regarding brand awareness, service development, and brand engagement. Many businesses observed an improve in sales, if social media were involved. [1] also state that there has been limited research to measure the impact of the use of social media on a business. The limited research available is mainly in the business area of marketing. Businesses have been found to be slower than consumers to adopt social media are. This is found to be the case, despite the high growth in consumers using social media and the identified advantages of using social media e.g. strengthening of customer relationships [2]. Major social media sites are Facebook, Twitter, Instagram, YouTube, LinkedIn, Google+, and Others.

\section{LITERATURE REVIEW}

[3] introduced "The role of social networks in influencing the purchasing decision of the consumer via the Internet"; this study measures the role of social networks to influence students purchasing decision making at Al-Qassim University, the study used the analytical Methodology to get to the results. The researcher developed a technique to measure the relationship between all variables in the study. A sample of (524) students was chosen from the University of Al-Qassim.

The study based on the descriptive analytical approach by reviewing the literature on the theoretical administrative web 2.0, social networks and online consumer purchasing behavior. The results indicated that the social networking dimensions (exchange of information, evaluation of product) possess an impact on the purchasing decision, while the results showed the absence of influential dimension on consumer support as one of the dimensions of social networking in influencing the purchasing decision.

No significant differences between males and females (sex and age variables), using social networks (exchange of information, evaluate the product, consumer support) due to the sex and age variable. In light of these findings, the study made a series of recommendations. The most important: the need for the managers, marketers, and web designers to understand web 2.0 features and the advantages offered through social networks. In addition, to understand the advantages and functions and tools of social communication and knowing how to apply them efficiently and effectively, and choose any of the areas of social networking. It needs to be improved and then use the appropriate social networking tool.

[5] performed a research on "Facebook Advertising: The Social Commerce Lifeline for Small Businesses" to understand how consumers interact with social media - especially Facebook - during the research and in-store stages of their shopping experience. The study performed on 1,000 US adults aged 1829 years old, who are interested in buying products and services from local/small businesses.

The results was $80 \%$ of respondents do their digital 'hunting' at least once a week before stepping into a physical store. $62 \%$ of respondents believe Facebook is most useful for researching small businesses before visiting in-person, compared to Twitter (11 percent) and Pinterest (12 percent). $58 \%$ of the 
respondents engage with Facebook advertising from a small business at least once a week before buying an item in-store.

$84 \%$ of respondents believe local deals/offers on Facebook are important in their decision to purchase an item in-store. $40 \%$ of respondents believe Facebook offers are most likely to influence them to make an in-store purchase from a small business.

$80 \%$ of the respondents are more likely to purchase products or services in-store from a small business if there are positive customer reviews/ratings on the company's website, mobile site or Facebook page. 38\% of respondents believe Facebook offers that can be redeemed in local stores are most likely to influence them to visit the website of a local/small business.

Restaurants (38 percent) take the lead in the type of business with the highest level of Facebook engagement. Meanwhile, beauty/spa (14 percent) and education/training (14 percent) tie for second place.

\section{SOCIAL NETWORKS MARKETING}

Marketing through the social networks, can be defined as the use of social networks for sales, marketing, public relations or customer service. These tools allow customers to interact with producers rather than a one-way communication, as it allows companies to open connection channels with the customers. The popularity of social networks growing steadily, and has provided businesses with unprecedented opportunities to deliver their marketing messages to their customers directly.

Production and services realized the importance of social networking as a means to promote their products and services, listening to customers in social networks, as well as in communication and interaction with their customers, and exchange information, such as videos, photos, texts and news. Companies can also use social networking to improve public relations, support channel, and to improve the possibilities for the sales department to deliver the highest value to its customers.

Social networking provides a strong environment for users to share and exchange views and experiences about things that matter most. Users employ social networking for various reasons, such as building a mental picture, access to information of interest and entertainment. The need to belong is one of the main driving motives to participate in a social network, which make it prominent at those of other traditional tools such as chat rooms, email, forums, and electronic publishing. The Internet and mobile web became a place that people's opinions are the driving force for social and commercial argument. The new era of consumer culture, mostly belong to the Internet and mobile web, in which the power shifted from organizations to individuals.

The electronic consumer behavior is no different from the traditional consumer. In both cases, various elements, such as product presentation, product handling, product quality, price, and many others influence the consumer behavior. The only difference is that the Internet and mobile web provide more tools to perform the following:

a. Marketing of Products \& Services

b. Online sales

c. Connecting with customers and suppliers

d. Brand support

e. Reduce costs

f. Contact businesses

\section{METHDOLOGY}

Based on the theory of a survey was created with questions relevant to how Internet and social media can help companies to increase marketing and sales. The methodology based on quantitative methods, and focusing on numerical data [6]. The researcher tries to find a repeated manner, to see if there is relationships between different variables. Since there is no data in this research about how companies integrate social media in their organization, it was decided to use a quantitative method.

\subsection{The study variables:}

The independent variable: social networks (The exchange of information - Product Rating Consumer support). The dependent variable: consumer intent to purchase.

\subsection{Participant selection:}

In this research, a random participant was used for the interviews and explain the questionnaire, which means that most of the interviewees were chosen from among young people between ages 21 to more than 30 years, simple random sampling, and area sampling. 


\section{DATA ANALYSES}

The survey was handled to (108) Kuwaiti and non-Kuwaiti (54 male, 54 female), divided into three groups (21 to 25, 26 - 30, more than 30) in all the six governorates of Kuwait. Eight questionnaire results were excluded for lack completeness and suitability for analysis, bringing the total number of valid questionnaires (100).

Data analysis for this research is to obtain the relationship between social media and marketing. The survey questions are presented in tables and diagrams in the Appendix.

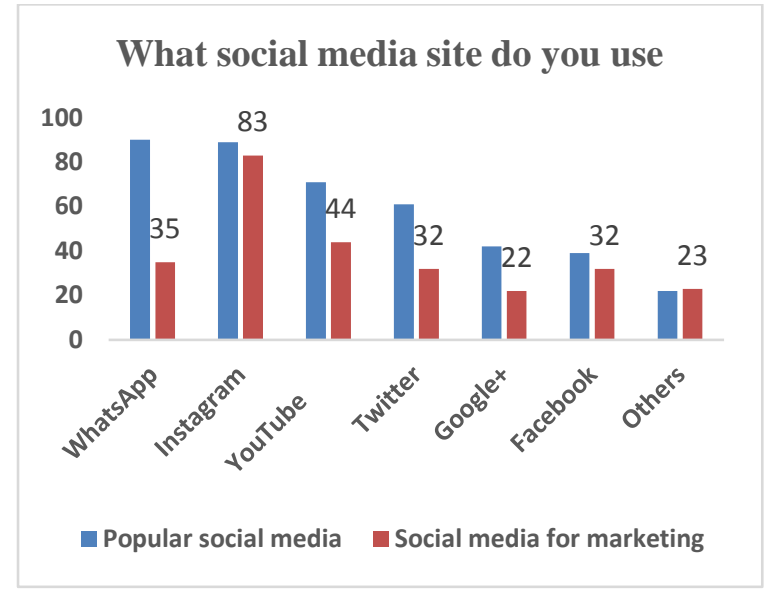

Figure 1. Use of Social Media

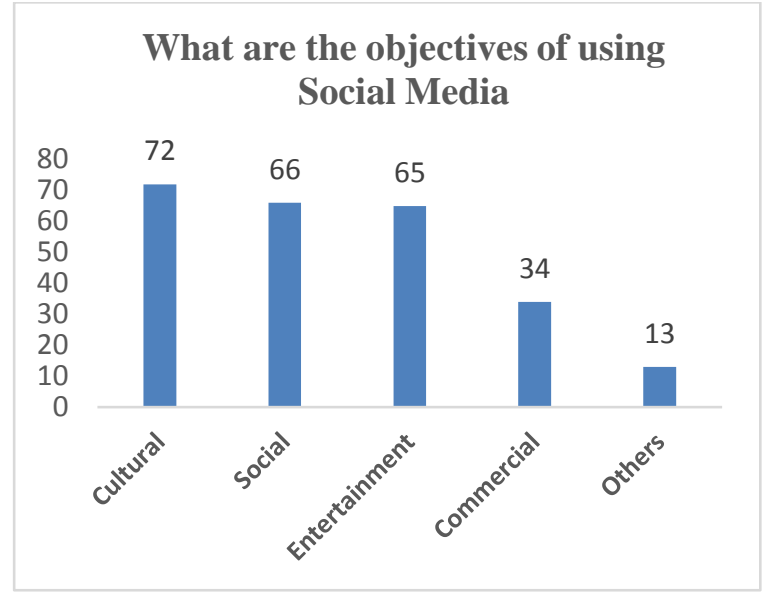

Figure 2. The Objectives of Using Social Media

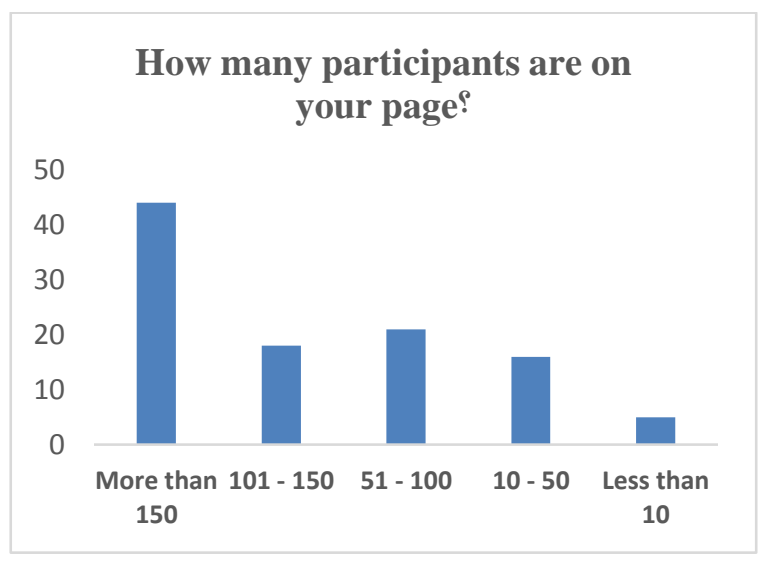

Figure 3. How Many Participants are on Your Page?

\section{RESULTS}

The study dealt with the role of the social networks on purchasing decisions, the three dimensions to the study concerning exchange of information; evaluate the product and consumer support. Most of the (100) respondents with a high degree education (46\% University, 43\% applied education).

a. The results showed no significant differences between males and females in perceptions about the influence of social networks to share information, evaluate the product, and consumer support. The same results obtained by [3].

b. There is a difference in the perceptions of the sample concerning product evaluation and product support between the age groups less than 21 years old and the age groups above. There is the heterogeneity between those two categories, this difference in favor to the above 21-age group; they are of the class that entered the field of work and have a steady income. The consciousness of the age group less than 21 concerning services that can be obtained from social networking will be less, compared to other age groups (above 21). As for the exchange of information on social networks, there are no differences among the perceptions of those age groups. 
c. The results indicated that the sample members who have visited social networking sites to search for their preferred products, shopping centers and restaurants, accounted for $12 \%$, while $42 \%$ indicated that they do so occasionally, and $46 \%$ said they do not. Either these results suggest a lack of the sample's reliance on social networks in the review of products, shopping centers and restaurants that they like, or that the manufacturers do not use social media effectively. The results are not matching Bhalla findings that $80 \%$ of respondents do their digital scanning at least once a week before intend to the store.

d. The result of read reviews, "likes" or recommendations for products, stores, and restaurants show that $36 \%$ answered yes, $45 \%$ sometimes, and $19 \%$ said no. This is a good sign, as the availability of information on the social networking helps to overcome the uncertainty for customers buying online. It indicates how to use the exchange of information in order to improve effective communication and marketing, and the role of verbal promotion in the marketing, and how it can be considered a confidence factor when buying products and services from websites. In addition, the important role of exchange of information and oral marketing in purchasing decisions-making mechanisms. Moreover, that the best marketing possible is through recommendations from friends. The same results obtained by Bhalla, $80 \%$ of the respondents will be encouraged if there are positive customer reviews/ratings on the company's website, and they will be more likely to purchase products or services in-store from a small business.

e. The unexpected results came from the question "traditional advertising (TV, Newspaper, Magazine, Billboards) are more effective than the social networking; $23 \%$ agreed, $36 \%$ said no, and $41 \%$ said sometimes.

f. The results indicate that online shoppers trust the information that is exchanged for the products more than any other means of advertising. In addition, even exchange of information did not lead to buying decision; it is providing many opportunities to gather information about it.

g. Exchange of product information with others in the social network improved dramatically. Their views increasingly a driving force in the field of trade and play an important role in other purchasing decisions. Shoppers are trusting - to some extent - information about a certain product posted by large number consumers more than any means of advertising.

h. As expected people are not $100 \%$ trusting information posted on social networking, $23 \%$ said no, $68 \%$ sometimes, and $9 \%$ trust the information.

i. Around $40 \%$ agree that social media increase knowledge and culture about products, restaurants and shopping center, $13 \%$ disagree, and $47 \%$ said sometimes. The result indicates that $87 \%$ of respondents have to surf social networking sites to increase their knowledge about the products before going over the points of sale.

j. About $34 \%$ of respondents were using social networking for commercial reasons. In addition, around $83 \%$ said that Instagram overcome most of the other social media (Twitter, Facebook, YouTube, etc.), and it is very important in their decision to purchase a product in stores. They are more likely to purchase a favorite item, products or services in store if there were positive customer reviews or ratings on the social media or the company's website. Product rating in some social networking, allows consumers to evaluate the product, and demonstrate either they prefer the product or not. Product rating evaluated on a scale one to five, one is the lowest, and five are the highest, which enables an easy way to measure how successful the product is. Product ratings are now common in many social media sites.

k. Around $23 \%$ of respondents do not trust information posted on social media, and $77 \%$ trust the information to certain extends.

1. Around $87 \%$ of respondents benefited from advertisements that appear in social media. They said that promotions and offers posted by small business on social media, sometimes better than that offered from the point of sales.

\section{RECOMNDATION}

To promote products and services in social networks, we recommend a communication mechanism among companies and consumers to improve updated support and knowledge.

The executives and sales representatives need to understand the benefits offered by social networks, and understand the advantages, functions, and tools of social communication, and knowing how to apply them effectively and efficiently, and then use the appropriate social networking tool. 


\section{CONCLUSION}

Keeps track of favorite products and retailers on social networks, consumers can access products details from inside the companies, as well as recognizing of new products, and available sales and promotions.

Medium and small businesses realized that the social networking helps the business sector on marketing and promotion of products and services, in addition, to achieve a strong communication with existing, and future consumers. These companies also confirmed that sales improved significantly if they interact with the participants in the social networks on a daily basis. Furthermore, sales improved, after posting restaurant menus, they received positive comments on the meals that they have requested. The next study will cover this point in detail.

\section{REFERENCES}

[1] Fischer, E. and Reuber, A. R. (2011). 'Social interaction via new social media: (How) can interactions on Twitter affect effectual thinking and behavior?' Journal of Business Venturing, 26 pp. 1-18.

[2] Andzulis, J. M., Panagopoulos, N. G. and Rapp, A. (2012) 'A Review of Social Media and Implications for the Sales Process.' Journal of Personal Selling \& Sales Management, 32(3) pp. 305-316.

[3] Abdel-qader, Mohamed. (2015). the role of social networks in influencing the purchasing decision of the consumer via the Internet, the Jordanian Journal of Business, Vol. 11, No. 1, 2015.

[4] Bharadwaj, Anandhi. El Sawy, Omar A. Pavlou, Paul A. Venkatraman, N. (2013), Digital Business Strategy: Toward a Next Generation of Insights, MIS Quarterly Vol. 37 No. 2, pp. 471-482/June 2013.

[5] Bhalla, Ragini. (2015). Facebook Advertising: The Social Commerce Lifeline for Small Businesses, GO Digital, www.godigitalmarketing.com on 2/09/2016

[6] Bryman, A. \& Bell, E. (2005). "F etagsekonomiska forskningsmetoder", 1st edition alm, Sweden: Liber Economy.R. Arulmozhiyal and K. Baskaran, "Implementation of a Fuzzy PI Controller for Speed Control of Induction Motors Using FPGA," Journal of Power Electronics, vol. 10, pp. 65-71, 2010.

\section{BIOGRAPHIES OF AUTHORS}

\begin{tabular}{l|l|} 
Khaled Abdulkareem Alenezi received his bachelor degree from Kuwait University in applied \\
statistics in 1987 and master degree in management system from Gulf University - Bahrain in \\
2010 . He received his PhD degree in computer science from International Islamic University \\
Malaysia (IIUM) in 2016. He is working at Central Agency for Information Technology- \\
Kuwait. His research interests include security, and he is expert in government sector security.
\end{tabular}

